\title{
Cerebro-meningeal infections in HIV-infected patients: a study of 116 cases in Libreville, Gabon.
}

\author{
Magloire Ondounda ${ }^{1}$, Chinenye Ilozue ${ }^{2}$, Caroline Magne $^{3}$
}

1. Department of Infectious and Tropical Diseases, Hôpital d'Instruction des Armées Omar Bongo

Ondimba, BP 20404 Libreville PK9, Gabon.magondounda@yahoo.fr

2. Department of Internal Medicine, Hôpital d'Instruction des Armées Omar Bongo Ondimba, BP 20404

Libreville PK9, Gabon. cilozue@doctors.org.uk

3. Department of Internal Medicine, Hôpital d'Instruction des Armées Omar Bongo Ondimba, BP 20404

Libreville PK9, Gabon.m2caroline@yahoo.fr

\begin{abstract}
Background: Cerebro-meningeal pathology is common in human immunodeficiency virus (HIV) infection and the aetiology is often difficult to ascertain with certainty.

Objective: To describe the major suspected and identified causes of meningeal or encephalitic syndromes in HIV infection in Libreville, Gabon.

Methods: A descriptive study using clinical records of patients hospitalised in the Department of Medicine in the Military Hospital of Libreville (Gabon) between January 2006 and May 2010. Clinical features were evaluated using multivariable logistic regression to evaluate association with the outcome of a clinical improvement or death.

Results: The most frequent neurological symptoms were reduced level of consciousness (54.3\%), headache (55.2\%), motor deficit $(38.7 \%$ ), and convulsions (36.2\%). Cerebral toxoplasmosis represented $64.7 \%$ of diagnoses, followed by cryptococcal neuromeningitis in $12.9 \%$ of cases. Tuberculoma was diagnosed in 4 cases and lymphoma in 2 cases. In $9.5 \%$ of cases, no aetiology was determined. Toxoplasmosis treatment led to clinical improvement in $69.3 \%$ of cases with suspected cerebral toxoplasmosis. Overall mortality was 39.7\%.

Conclusion: The diagnosis of neurological conditions in HIV positive patients is difficult, particularly in a low-resource setting. A trial of treatment for toxoplasmosis should be initiated first line with all signs of neurological pathology in a patient infected with HIV.
\end{abstract}

Keywords: Cerebral lesion, neuromeningitis, HIV, Libreville, Gabon.

DOI: http://dx.doi.org/10.4314/ahs.v16i2.31

Cite as: Ondounda M, Ilozue C, Magne C. Cerebro-Meningeal infections in HIV-infected patients: a study of 116 cases in Libreville, Gabon. Afri Health Sci 2016;16(2): 603-610. bttp://dx.doi.org/10.4314/abs.v16i2.31

\section{Introduction}

Neurological symptoms occur frequently in HIV positive
Corresponding author:
Chinenye Ilozue,
Department of Internal Medicine,
Hôpital d'Instruction des Armées
Omar Bongo Ondimba,
BP 20404 Libreville PK9, Gabon.
P.O. Box 53300, London,
United Kingdom, N3 9AU,
Tel. $+44(0) 7779104055$
Fax. +44(0)2083684426
Email: cilozue@doctors.org.uk

individuals with the brain and meninges often the site of opportunistic pathology due to reduced immunity and the neurotropism of the virus ${ }^{1,2}$. Studies at autopsy have shown that the brain is the second most affected organ after the lungs in patients infected with $\mathrm{HIV}^{3}$. The most frequent cause of neurological disease in HIV seropositive patients is an infectious agent, principally Toxoplasma gondii, Cryptococcus neoformans and Mycobacterium tuberculosis in endemic areas ${ }^{4,5}$. These may present as a neuromeningitis syndrome with or without cerebral lesions visible on brain imaging. The differential diagnosis is wide and includes cerebral lymphomas, progressive multifocal leucoencephalopathy (PML), Cytomegalovirus (CMV), Aspergillus and Nocardia infection ${ }^{1}$. In Gabon, the HIV prevalence among adults is estimated at 5.3\% and 
the population is also endemic for tuberculosis infection ${ }^{6}$. Toxoplasmosis is common with seroprevalence reaching over $70 \%$ in some areas ${ }^{7}$. The accurate diagnosis of these neurological conditions is difficult due to the variation in clinical features and this is even more challenging in a setting with limited technical diagnostic capabilities, notably a lack of cerebral biopsy ${ }^{2,4}$. The diagnostic approach is presumptive, despite evidence that there is poor accuracy of diagnosis without the gold standard of brain biopsy ${ }^{2}$. Most HIV-infected patients presenting with neurological symptoms are presumptively initiated on treatment for toxoplasmosis with the addition of broad spectrum antibiotics and tuberculosis (TB) treatment depending on therapeutic response. Diagnostic guidelines for the industrialised countries of Europe and the USA may not be appropriate for developing countries as the aetiologies of brain lesions differ. Thus the clinical evolution is often the cornerstone for assessing diagnostic accuracy ${ }^{4}$.

The objective of this study was to describe the principal diagnoses of neurological diseases in adult patients infected with HIV at the military hospital of Libreville, Gabon. The clinical outcomes of these conditions were also described.

\section{Methods}

This retrospective descriptive study was carried out in the department of medicine at the military hospital of Libreville, Gabon (l'Hôpital d'Instruction des Armées Omar Bongo Ondimba, HIA OBO). This is a large tertiary hospital providing medical (internal medicine, cardiology, respiratory, neurology, infectious diseases), surgical (general surgery, cardiothoracics, ear, nose \& throat, gynaecology, orthopaedics, ophthalmology), paediatric and maternity services to the local population. Diagnostic facilities are relatively comprehensive and include computed tomography $(\mathrm{CT})$ in the radiology department and laboratory services.

Medical records of patients admitted between January 2006 and May 2010 were examined retrospectively. We included adult patients (age $>18$ years) with positive HIVserology, with at least one of the following: A clinical presentation of meningitis or encephalitis, a motor deficit, an abnormal brain scan (CT or magnetic resonanceimaging, MRI) or cytological, biochemical or microbiological abnormalities of cerebrospinal fluid (CSF). There was no post-mortem evidence available from the patients who died to contribute to the definitive diagnosis.
Patients with unknown or indeterminate HIV status and those with incomplete medical records were excluded (all patients presenting for acute admission in the department of Medicine at HIA OBO receive an HIV test and thus this represented a minimum of cases. Many patients had been previously diagnosed with HIV infection and were known to the department of Infectious Diseases). Details of the clinical features and outcome were collected on a standardised data sheet for each case.

The database was created with EpiInfoTM 3.5.1. Demographic and clinical features were analysed to identify any associations with the outcome measures of "clinical improvement" and "death". Multivariable logistic regression was performed using SPSS 17.0.

The study was carried out in full compliance with all ethical principles for medical research involving human subjects as set out in the Declaration of Helsinki

\section{Results}

One hundred and sixteen records were included in the series. The median age of the patients was 40 years (range 19-73 years), with a male:female ratio of 1:32. The median delay to consultation was 7 days (range 1-60 days). (Table 1)

The predominant non-pecific symptoms were fever in $62(53.4 \%)$ patients and asthenia in $44(37.9 \%)$. The most frequent neurological symptoms were headache in $64(55.2 \%)$ patients, reduced level of consciousness in 63 $(54.3 \%)$ patients, motor deficit in $46(38.7 \%)$ and seizure in $42(36.2 \%)$. Sixty-four patients exhibited more than one clinical symptom/sign.

Cerebral CT or MRI scan was performed in 88 (75.9\%) patients of which $48(54.5 \%)$ had cerebral oedema and $46(52.3 \%)$ had a cerebral abscess with a mass effect in $35(39.8 \%)$. Multiple cerebral lesions were found in 31 (35.2\%) patients. Twenty-three $(26.1 \%)$ patients had a normal CT brain scan. CSF analysis was carried out in 64 patients of which $11(17.2 \%)$ had no abnormality. The majority of CSF analyses had subtle abnormalities of glucose and protein.

Cerebral toxoplasmosis was the most frequent diagnosis with $75(64.7 \%)$ cases, of which $44(58.7 \%)$ had cerebral abscesses (26 with multiple lesions) and 6 had another pathology diagnosed on the same admission. The diagnosis was made based on clinical symptoms, features of CT/ MRI brain imaging and positive therapeutic response. Cryptococcal neuromeningitis was the second most frequent diagnosis, found in 15 patients $(12.9 \%)$. This diag- 
nosis was confirmed by detection of $\mathrm{C}$. neoformans in the CSF. India ink was positive in 14 cases and cryptococcal polysaccharide antigen was detected in one patient. Bacterial meningitis and stroke occurred in $8(6.9 \%)$ and $6(5.2 \%)$ patients respectively. In the absence of a formal diagnosis, the presumptive diagnosis of cerebral tuberculoma (TB) was made in 4 patients and lymphoma in 2 patients. There was dual pathology diagnosed in $7(6 \%)$ of cases, the majority including toxoplasmosis with tuberculosis (TB), cryptococcal neuromeningitis, immune reconstitution inflammatory syndrome (IRIS), stroke (not definite) and pyogenic abscess. Cryptococcal neuromeningitis with TB was also a dual diagnosis made in 1 patient. In $9.5 \%$ of cases (11 patients) the diagnosis was undetermined due to the patients dying before investigations could be carried out. (Table 1)

Table 1: Demographic, clinical and diagnostic profile of total population

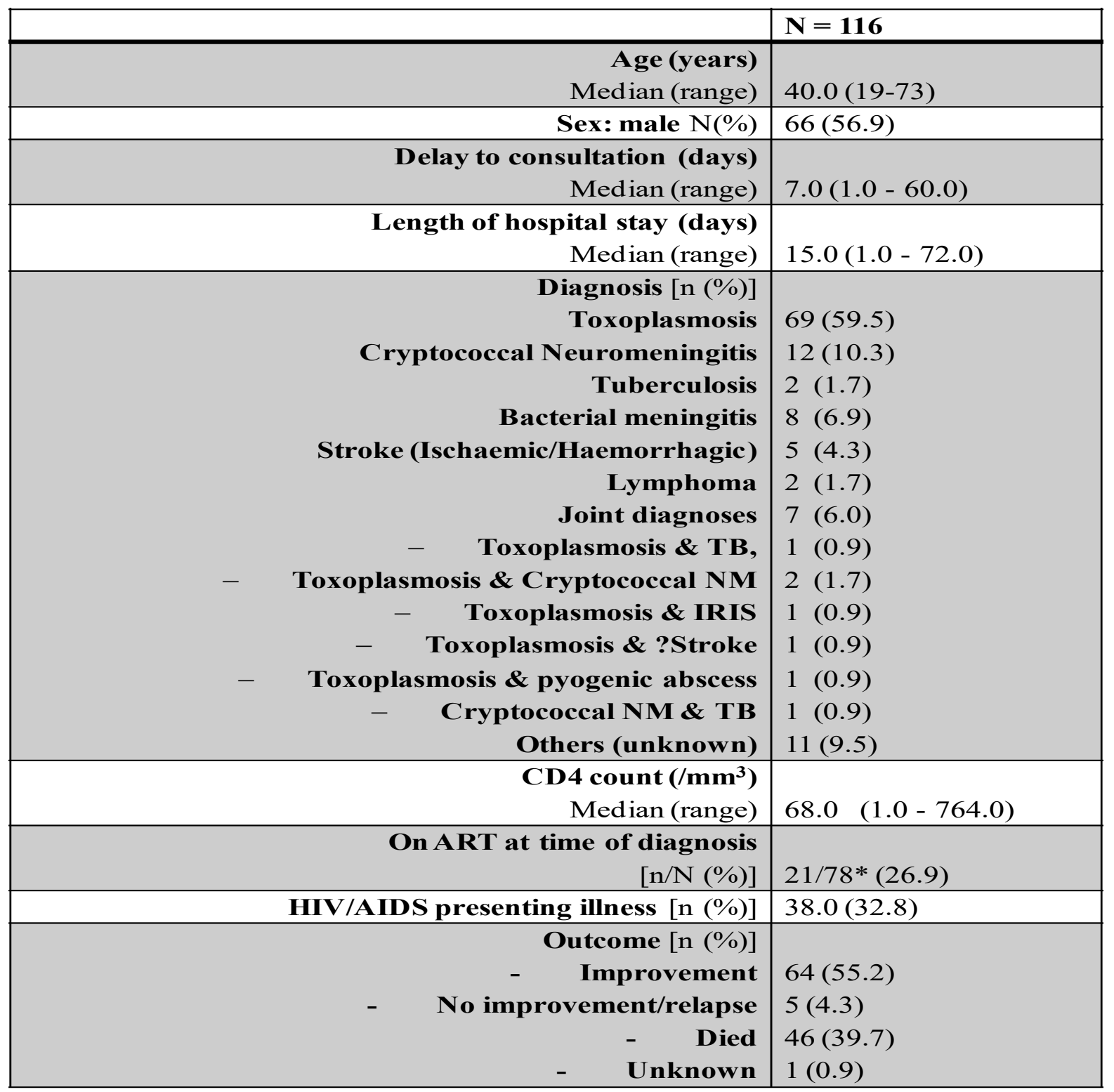

NM - neuromeningitis ; IRIS - immune reconstitution inflammatory syndrome ; TB - tuberculosis ; ART antiretroviral therapy ; HIV - human immunodeficiency virus ; AIDS - acquired immune deficiency syndrome *78 patients previously diagnosed with HIV. 
At the time of diagnosis of the neurological condition, 38 patients $(32.8 \%)$ were unaware of their HIV status and $26.9 \%$ of those with known HIV infection were receiving antiretroviral treatment (ART). The median CD4 lymphocyte count was $68 / \mathrm{mm}^{3}$ with a range of $1-764 / \mathrm{mm}^{3}$. Sixty-four (55.4\%) patients showed clinical improvement, defined as improvement in clinical signs and symptoms within 2 weeks and/or improvement in radiological appearances up to two months after treatment. All of the 75 patients diagnosed with toxoplasmosis received pyrimethamine and sulfadiazine treatment with folic acid, resulting in a clinical improvement in 52 (69.3\%). Patients with other diagnoses received various combinations of treatments according to the individual context, namelyantibiotics, antifungals, antiparasitic and antituberculosis treatment. The median length of hospital stay was 15 days (1-72). Overall mortality was $39.7 \%$.

In the multivariable logistic regression analysis, evaluating the clinical features associated with the outcomes of clinical improvement or death, shorter length of stay, male sex and reduced level of consciousness were associated with death. Presence of a cerebral abscess (OR 0.002, $95 \% \mathrm{CI} 0.0001-0.131, \mathrm{p}=0.004)$ and a diagnosis of toxoplamosis (OR 0.02, 95\%CI 0.001-0.48, $\mathrm{p}=0.015$ ) were inversely associated with death. Age, CD4 count, prior ARV therapy and delay to consultation did not appear to have any correlation with mortality in this population. A clinical improvement was associated with a diagnosis of toxoplasmosis and higher CD4 count. Male gender, altered level of consciousness and a cerebral lesion with mass effect had an inverse relationship with a good clinical outcome. (Table 2) 
Table 2: Results of multivariable logistic regression analysis of variables associated with clinical outcomes.

\begin{tabular}{|c|c|c|c|c|c|c|}
\hline Variable & $\begin{array}{l}\frac{\text { Clinical }}{\text { Improvement }} \\
\frac{n=64}{\mathrm{R}^{2}=0.641}\end{array}$ & & & $\begin{array}{l}\frac{\text { Died }}{n=46} \\
\mathrm{R}^{2}=0.678\end{array}$ & & \\
\hline & $\begin{array}{l}\text { Median (range) } \\
\mathrm{N}(\%)\end{array}$ & Odds Ratio $(95 \%$ Cl) & p-value & $\begin{array}{l}\text { Median (range) } \\
\text { N (\%) }\end{array}$ & $\begin{array}{l}\text { Odds Ratio } \\
(95 \% \text { CI })\end{array}$ & p-value \\
\hline Age (years) & $39(21-67)$ & $0.94(0.83,1.07)$ & 0.339 & $41(19-73)$ & $0.99(0.87,1.13)$ & 0.911 \\
\hline Sex (male) & $31(48.4)$ & $0.08(0.01,0.65)$ & 0.018 & $30(65.2)$ & $29.2(1.57,540.4)$ & 0.024 \\
\hline Length of stay (days) & $18(3-72)$ & $1.04(0.98,1.11)$ & 0.228 & $8(1-45)$ & $0.92(0.86,0.99)$ & 0.027 \\
\hline Delay to consultation (days) & $7(1-34)$ & $0.97(0.87,1.08)$ & 0.563 & $9(3-60)$ & $1.02(0.90,1.14)$ & 0.799 \\
\hline CD4 count $\left(/ \mathrm{mm}^{3}\right)$ & $51.5(3-764)$ & $1.01(1.00,1.02)$ & 0.047 & $79(1-475)$ & $0.99(0.985,1.00)$ & 0.199 \\
\hline Fever & $38(59.4)$ & $2.42(0.25,23.6)$ & 0.447 & $21(45.7)$ & $0.50(0.04,5.77)$ & 0.579 \\
\hline Asthenia & $23(35.9)$ & $0.17(0.02,1.58)$ & 0.119 & $19(41.3)$ & $8.47(0.63,113.2)$ & 0.106 \\
\hline Weight loss & $17(26.6)$ & $0.98(0.16,5.89)$ & 0.980 & $15(32.6)$ & $0.38(0.04,3.37)$ & 0.387 \\
\hline Headache & $32(50.0)$ & $0.73(0.13,4.08)$ & 0.721 & $29(63.0)$ & $2.14(0.29,16.1)$ & 0.459 \\
\hline Reduced consciousness & $33(51.6)$ & $0.09(0.01,0.73)$ & 0.025 & $29(63.0)$ & $21.9(1.74,274.1)$ & 0.017 \\
\hline Convulsions & $29(45.3)$ & $2.45(0.39,15.5)$ & 0.340 & $12(26.1)$ & $0.16(0.01,1.92)$ & 0.150 \\
\hline Hemiplegia/Hemiparesis & $27(42.2)$ & $0.57(0.84,3.80)$ & 0.558 & $15(32.6)$ & $1.19(0.14,9.93)$ & 0.873 \\
\hline Psychomotor agitation & $20(31.3)$ & $4.32(0.50,37.3)$ & 0.184 & $7(15.2)$ & $0.43(0.04,4.77)$ & 0.495 \\
\hline Meningism & $9(14.1)$ & $0.67(0.07,6.76)$ & 0.733 & $7(15.2)$ & $1.21(0.09,16.5)$ & 0.884 \\
\hline Visual symptoms & $8(12.5)$ & $0.83(0.07,9.95)$ & 0.880 & $5(10.9)$ & $0.19(0.01,7.21)$ & 0.368 \\
\hline Cerebral abscess & $34(53.1)$ & $148.7(1.9,11680.6)$ & 0.025 & $10(21.7)$ & $0.002(0.0001,0.131)$ & 0.004 \\
\hline Multiple cerebral lesions & $15(23.4)$ & $0.14(0.02,1.29)$ & 0.083 & $14(30.4)$ & $8.26(0.63,108.4)$ & 0.108 \\
\hline Cerebral oedema & $32(50.0)$ & $7.21(0.39,134)$ & 0.186 & $13(28.3)$ & $3.02(0.06,150.4)$ & 0.579 \\
\hline Cerebral lesion with mass effect & $22(34.4)$ & $0.004(0.00,0.38)$ & 0.017 & $9(19.6)$ & $48.3(0.92,2528.4)$ & 0.055 \\
\hline Normal CT & $10(15.6)$ & $7.72(0.59,101)$ & 0.119 & $13(28.3)$ & $0.16(0.01,2.65)$ & 0.203 \\
\hline Prior ARV therapy & $12(18.8)$ & $5.13(0.37,71.2)$ & 0.223 & $7(15.2)$ & $0.05(0.002,1.299)$ & 0.072 \\
\hline HIV/AIDS presenting illness & $20(31.3)$ & $2.14(0.24,18.7)$ & 0.493 & $15(32.6)$ & $0.09(0.01,1.19)$ & 0.067 \\
\hline Diagnosis of toxoplasmosis & $52(81.3)$ & $54.1(3.77,776)$ & 0.003 & $20(43.5)$ & $0.02(0.001,0.48)$ & 0.015 \\
\hline
\end{tabular}




\section{Discussion}

Central nervous system disorders associated with HIV infection occur most commonly at an advanced stage of immunosuppression ${ }^{8,10}$. In Gabon, neurological diseaseassociated with HIV infection is poorly described, most likely due to the lack of diagnostic resources, particularly stereotactic biopsy. Thirty-eight of our patients wereunaware of their HIV serological status and presented in clinical stage 3 according to the Centre for Disease Control (CDC) criteria $^{11}$. Similar late first presentations of HIV/AIDS have been described in other series. This diagnostic delay may be linked to the poor participation in voluntary testing for HIV due to stigmatisation anddiscrimination associated with the diagnosis ${ }^{12,13}$. This is compounded by issues of poor access to health care and cultural and traditional beliefs that cause such late presentation in Gabon and other African regions where many people still believe that AIDS is a disease of misfortune and prefer "traditional medicine" interventions ${ }^{12}$.

The difficulty in establishing a diagnosis is due to the non-specific nature of the symptoms. Space-occupying intracerebral lesions often present with ill-defined neurological signs and symptoms. Cerebral imaging (CT/MRI), although an important contributor to the diagnosis of brain lesions, is limited by the relatively poor specificity of the images observed. This results in great difficulty establishing a diagnosis with certitude, especially in a setting of limited human resources ${ }^{8,14}$.

Cerebral toxoplasmosis remains the principal aetiology of intracranial space occupying lesions (SOL) and the number one opportunistic infection of the nervous system in patients infected with $\mathrm{HIV}^{8,15,16}$. Single or multiple cerebral abscesses are most frequently observed, and diffuse encephalitis (with normal CT appearance) is rarer ${ }^{2,8}$. In our study, $58.7 \%$ of patients suspected of toxoplasmosis had one or more space occupying lesions. Toxoplasma gondii serology would have contributed little to the diagnosis but negative serology may have made the diagnosis less likely ${ }^{17,18}$. Twenty percent of our patients presenting with neurological symptoms had a normal CT brain scan which did not eliminate the diagnosis of cerebral toxoplasmosis ${ }^{19}$. The problem arises when there is lack of clinical improvement with anti-toxoplasmosis treatment (as judged appropriate). In these cases the difficulty is in knowing if the case represents an authentic toxoplasmosis unresponsive to treatment or another opportunistic or associated pathology, making the evaluation of the presumptive treatment very difficult using outcome criteria alone $^{2}$. Cerebral biopsy, with sensitivity upto $93 \%,{ }^{20}$ becomes even more important in such cases.

In our study a trial of treatment with anti-toxoplasmosis agents in those with a presumed diagnosis of toxoplasmosis led to clinical improvement in $69.3 \%$ of patients, a result similar to that found in other studies ${ }^{21}$.

In endemic countries the appearance of cerebral tuberculoma is associated with HIV infection ${ }^{22,23}$. However, in our experience, extrapulmonary forms of TB can oftenoccur independently of HIV status ${ }^{24}$. The clinical signs of cerebral tuberculoma are generally those of any space occupying lesion and the diagnosis is difficult by means of CT or MRI in the absence of a clinical context of progressive TB. A diagnosis of certitude is made possible by bacteriological data and histopathology. In our study, inthe absence of clinical improvement with anti-Toxoplasma treatment, the diagnosis of tuberculoma was made in 4 patients presenting with progressive pulmonary TB disease (miliary TB). Cerebral lymphoma was presumed in 2 cases. Lymphoma represents $2 \%$ of cerebral masses in AIDS and appears most often at advanced levels of immunosuppression and lower CD4 counts ${ }^{25,26}$. In this study the median CD4 count was $68 / \mathrm{mm}^{3}$ with a minimum count of $1 / \mathrm{mm}^{3}$, which is concordant with other studies showing equally advanced stages of immunocompromise in CNS disease $\mathrm{e}^{2,27,28}$.

Cryptococcal neuromeningitis is another very common cause of neurological disease in HIV positive patients ${ }^{5}$, ${ }^{29}$. The diagnosis rests on identification of the fungus in the CSF by either india ink staining, the detection of the polysaccharide antigen or culture. However, in AIDS, CSF changes are sometimes atypical and non-specific,making the diagnosis of any neurological infection troublesome ${ }^{2}$. We diagnosed 15 cases of cryptococcal neuromeningitis, representing $12.9 \%$ of aetiologies and the second cause of CNS opportunistic infection in this population, similar to that found in other regions of sub-Saharan Africa ${ }^{5}$, ${ }^{29,30}$. Other neuromeningeal manifestations may be attributable to cytomegalovirus, herpes virus or JC virus. None of these aetiologies were found in our population, likely 
due to diagnostic limitations. Seven of the patients had more than one pathology and 11 had no diagnosis made. Previous studies have remarked on the concurrence of several pathologies in a single cerebral lesion in HIV positive patients ${ }^{2,5}$.

Overall mortality was $39.7 \%$ and there were proportionally fewer deaths in patients diagnosed with cerebral toxoplasmosis compared to other diagnoses. However, several patients died before a diagnosis could be made. In these cases autopsy studies would be of great diagnostic utility $^{3,9}$. In this setting autopsy is not common practice.

The primary limitations are inherent to all retrospective studies: the medical records often had missing information and a number of useful investigations were not carriedout at the time of hospitalisation for a large number of patients. This limits the amount of information that could be obtained and reduces the applicability of the logistic regression models. Secondly, each diagnosis (except cryptococcosis and bacterial meningitis that were proven on CSF) was presumptive, resulting in a limitation in comparative analyses between pathologies. Some HIV positive patients presenting with headache as the only manifestation of neuro-meningeal disease would have been excluded from the analysis, potentially missing important information. There is a risk of selection bias significantly affecting the series in that certain patients may have been excluded due to this lack of neuro-meningeal manifestation and, perhaps, indeterminate HIV test at admission. These potentially HIV positive patients may have been infected by other organisms that have been missed by this series.

This descriptive study of neurological conditions in HIV positive patients identified cerebral toxoplasmosis as the principal diagnosis., As such, empirical treatment for cerebral toxoplasmosis in a HIV positive patient seems reasonable in the context of cerebromeningeal pathology, especially if the CT is suggestive(e.g. demonstrating a cerebral abscess). Other diagnoses such as cryptococcal meningitis, bacterial meningitis and stroke must also be considered as described in this population. The occurrence of multiple pathologies must also be borne in mind by clinicians as demonstrated by the results of this study. The beneficial role of prophylaxis against opportunistic infections is incontestable and must be a priority in the management of HIV positive patients in this setting.
There must also be strengthening of preventative programmes and HIV voluntary testing so that patients are not diagnosed at such late stages of disease.

\section{Acknowledgements}

With gratitude to Prof JR Nzenze for permission to carry out the study in his department.

\section{Conflicts of interest}

None to declare

\section{References}

1. Montoya JG, Liesenfeld O. Toxoplasmosis. Lancet. 2004;363(9425):1965-76.

2. Skiest DJ. Focal neurological disease in patients with acquired immunodeficiency syndrome. Clin Infect Dis. 2002;34(1):103-15.

3. Gray F, Chretien F, Vallat-Decouvelaere AV, Scaravilli F. The changing pattern of HIV neuropathology in the HAART era. J Neuropathol Exp Neurol. 2003;62(5):429-40. 4. Modi M, Mochan A, Modi G. Management of HIV-associated focal brain lesions in developing countries. QJM. 2004;97(7):413-21.

5. Jowi JO, Mativo PM, Musoke SS. Clinical and laboratory characteristics of hospitalised patients with neurological manifestations of HIV/AIDS at the Nairobi hospital. East Afr Med J. 2007;84(2):67-76.

6. WHO. Global Health Observatory: WHO; 2010 [20 June 2010]. Available from: http://apps.who.int/ghoda$\mathrm{ta} /$.

7. Nabias R, Ngouamizokou A, Migot-Nabias F, MbouMoutsimbi RA, Lansoud-Soukate J. [Serological investigation of toxoplasmosis in patients of the M.I.P. center of Franceville (Gabon)]. Bull Soc Pathol Exot. 1998;91(4):31820.

8. American Academy of Neurology. Evaluation and management of intracranial mass lesions in AIDS. Report of the Quality Standards Subcommittee of the American Academy of Neurology. Neurology. 1998;50(1):21-6.

9. World Health Organisation. Global Health Observatory: WHO; 2010 [20 June 2010]. Available from: http:/ / apps.who.int/ghodata/.

10. Abgrall S, Rabaud C, Costagliola D. Incidence and risk factors for toxoplasmic encephalitis in human immunodeficiency virus-infected patients before and during the highly active antiretroviral therapy era. Clin Infect Dis. 2001;33(10):1747-55. 
11. Centers forDisease Control and Prevention. Revised Surveillance Case Definitions for HIV Infection Among Adults, Adolescents, and Children Aged <18 Months and for HIV Infection and AIDS Among Children Aged 18 Months to <13 Years --- United States, 20082008 [28 PubMed June 2010]. Available from:http://www. cdc.gov/mmwr/preview/mmwrhtml/rr5710a1.htm?s_ cid $=$ rr5710a1_e.

12. Manga NM, Diop SA, Ndour CT, Dia NM, Mendy A, Coudec M, et al. [Late diagnosis of HIV infection in the Fann, Dakar clinic of infectious diseases: testing circumstances, therapeutic course of patients, and determining factors]. Med Mal Infect. 2009;39(2):95-100.

13. Okome-Nkoumou M, Okome-Miame F, Kendjo E, Obiang GP, Kouna P, Essola-Biba O, et al. Delay between first HIV-related symptoms and diagnosis of HIV infection in patients attending the internal medicine department of the Fondation Jeanne Ebori (FJE), Libreville, Gabon. HIV Clin Trials. 2005;6(1):38-42.

14. Smego RA, Jr., Orlovic D, Wadula J. An algorithmic approach to intracranial mass lesions in HIV/AIDS. Int J STD AIDS. 2006;17(4):271-6.

15. Mielke J. Neurological complications of human immunodeficiency virus infection in Zimbabwe-2005. J Neurovirol. 2005;11 Suppl 3:23-5.

16. Bhigjee AI, Naidoo K, Patel VB, Govender D. Intracranial mass lesions in HIV-positive patients--the KwaZulu/Natal experience. Neuroscience AIDS Research Group. S Afr Med J. 1999;89(12):1284-8.

17. Walker M, Zunt JR. Parasitic central nervous system infections in immunocompromised hosts. Clin Infect Dis. 2005;40(7):1005-15.

18. Mathews C, Barba D, Fullerton SC. Early biopsy versus empiric treatment with delayed biopsy of nonresponders in suspected HIV-associated cerebral toxoplasmosis: a decision analysis. AIDS. 1995;9(11):1243-50. 19. Weenink JJ, Weenink AG, Geerlings SE, van Gool T, Bemelman FJ. Severe cerebral toxoplasma infection cannot be excluded by a normal CT scan. Neth J Med. 2009;67(4):150-2.

20. Antinori A, Ammassari A, De Luca A, Cingolani A, Murri R, Scoppettuolo G, et al. Diagnosis of AIDS-related focal brain lesions: a decision-making analysis based on clinical and neuroradiologic characteristics combined with polymerase chain reaction assays in CSF. Neurology. 1997;48(3):687-94.

21. Millogo A, Sawadogo AB, Lankoande D, Ouedraogo I. Diagnostic problems of expansive intracranial process in HIV infected patients of the Bobo-Dioulasso Central Hospital (Burkina Faso)]. Bull Soc Pathol Exot. 2001;94(4):315-8.

22. Kumar Garg R, Kumar Singh M, Misra S. Singleenhancing CT lesions in Indian patients with seizures: a review. Epilepsy Res. 2000;38(2-3):91-104. PubMed

23. Ravenscroft A, Schoeman JF, Donald PR. Tuberculous granulomas in childhood tuberculous meningitis: radiological features and course. J Trop Pediatr. 2001;47(1):512.

24. Ondounda M, Ilozue C, Mounguengui D, Magne C, Nzenze JR. [Clinical and radiological features of tuberculosis during HIV infection in Libreville, Gabon]. Med Trop (Mars). 2011;71(3):253-6.

25. Frisch M, Biggar RJ, Engels EA, Goedert JJ. Association of cancer with AIDS-related immunosuppression in adults. $J A M A$. 2001;285(13):1736-45.

26. Saple DG, Shah I, Surjushe AU, Murthy A, Chudgar P, Gote PD. Lymphoma in HIV patients: Varied presentations. Indian J Med Paediatr Oncol.31(1):39-42.

27. Nissapatorn V, Lee C, Quek KF, Leong CL, Mahmud $\mathrm{R}$, Abdullah KA. Toxoplasmosis in HIV/AIDS patients: a current situation. Jpn J Infect Dis. 2004;57(4):160-5.

28. Colombo FA, Vidal JE, Penalva de Oliveira AC, Hernandez AV, Bonasser-Filho F, Nogueira RS, et al. Diagnosis of cerebral toxoplasmosis in AIDS patients in Brazil: importance of molecular and immunological methods using peripheral blood samples. J Clin Microbiol. 2005;43(10):5044-7.

29. Katwere M, Kambugu A, Piloya T, Wong M, HendelPaterson B, Sande MA, et al. Clinical presentation and aetiologies of acute or complicated headache among HIVseropositive patients in a Ugandan clinic. J Int AIDS Soc. 2009;12(1):21 PubMed.

30. Souksouna G, Mbala-Amougou J, Toukam M, SendeNgonde C, Juimo A. Cerebral lesions in AIDS correlated with CD4 count at the Yaoundé general hospital [Lésions cérébrales au cours du sida corrélées au taux de CD4 à l'hôpital général de Yaoundé]. Sidanet. 2006;3(1):901 PubMed. 